\title{
VEGF alleviates lower limb ischemia in diabetic mice by altering muscle fiber types
}

\author{
LIJING JIA $^{1,2^{*}}$, PEILIN ZHENG ${ }^{2 *}$, HONGBO WANG ${ }^{3 *}$,

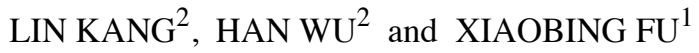 \\ ${ }^{1}$ Laboratory of Wound Healing and Cell Biology, Institute of Basic Medical Science, \\ Chinese People's Liberation Army General Hospital, Beijing 100048; ${ }^{2}$ Department of Endocrinology, \\ Shenzhen People's Hospital, The Second Clinical Medical College of Jinan University, \\ The First Affiliated Hospital of Southern University of Science and Technology, Shenzhen, Guangdong 518020; \\ ${ }^{3}$ Department of Respiratory Medicine, Tianjin Children's Hospital, Tianjin 300134, P.R. China
}

Received July 26, 2020; Accepted January 8, 2021

DOI: $10.3892 /$ etm.2022.11176

\begin{abstract}
Lower limb ischemia caused by diabetic foot (DF) is one of the most serious complications of diabetes. The therapeutic role of VEGF in DF is well documented. However, the mechanism for action of VEGF is still not clear. The present study aimed to explore the effects of VEGF-mediated skeletal muscle fiber type switch in angiogenesis and the treatment of DF. C57BL/6 mice housed in cages equipped with a voluntary running wheel were used to access VEGF protein level and citrate synthase activity (by ELISA) as well as muscle fiber type changes (by immunofluorescence) in the gastrocnemius muscle. C57BL/6 mice were fed on a high-fat diet for 6 weeks and then injected with streptozocin to induce diabetic lower limb ischemia model. Control adenovirus (Ad-GFP) or Ad-VEGF-GFP were then injected into the left gastrocnemius of the ischemic diabetic mice. Blood flow perfusion was examined by laser Doppler imaging at 1, 3, 7 and 14 days after adenovirus transduction. On day 14 , all mice were anesthetized and sacrificed. VEGF expression levels, citrate synthase activity and muscle fiber type changes in the gastrocnemius
\end{abstract}

Correspondence to: Professor Lijing Jia, Department of Endocrinology, Shenzhen People's Hospital, The Second Clinical Medical College of Jinan University, The First Affiliated Hospital of Southern University of Science and Technology, 1017 Dongmen North Street, Shenzhen, Guangdong 518020, P.R. China

E-mail: jialijing2012@126.com

Dr Xiaobing Fu, Laboratory of Wound Healing and Cell Biology, Institute of Basic Medical Science, Chinese People's Liberation Army General Hospital, 28 Fuxing Road, Beijing 100048, P.R. China E-mail: fuxiaobing@vip.sina.com

*Contributed equally

Key words: vascular endothelial growth factor, skeletal muscle fiber type, lower limb ischemia, angiogenesis muscle were assayed by ELISA and immunofluorescence analysis of myosin heavy chain IIa (MHCIIa) expression, respectively. Transwell assays were performed to determine whether VEGF-treated C2C12 myotubes played a role on tubule formation and migration of HUVECs. It was found that VEGF levels and citrate synthase activity were upregulated after voluntary exercise, along with the increased frequency of oxidized muscle fibers. Notably, adenovirus-mediated VEGF overexpression in the muscle also increased the frequency of oxidized (MHCIIa-positive) muscle fibers, enhanced citrate synthase activity and ameliorated lower limb ischemia in diabetic mice. VEGF treatment enhanced the phosphorylation of PI3K, Akt and AMPK (assayed by western blotting), as well as glucose consumption and metabolism (assayed by western blotting and glucose uptake assay), in the $\mathrm{C} 2 \mathrm{C} 12$ myotubes. Interestingly, VEGF-treated $\mathrm{C} 2 \mathrm{C} 12$ myotubes promoted the migration and tubule formation of HUVEC cells. The present findings suggest that skeletal muscle fiber conversion might be a potential approach for VEGF-mediated angiogenesis and disease treatment, which may provide new options for the prevention and treatment of DF.

\section{Introduction}

Diabetes and the complications arising from it have become a global public health problem. The rate of lower limb amputation is between $0.2-4.8 \%$ in diabetic patients worldwide, which is 25 times higher compared with that among non-diabetic individuals $(1,2)$. A total of $85 \%$ of amputations occur after foot ulcers among diabetic patients. Peripheral artery disease (PAD) is not only the most important risk factor for diabetic foot (DF) ulcers, but also an independent factor to predict the outcome and recovery in patients with DF ulcers $(3,4)$.

To date, the treatment of diabetic peripheral vascular lesions is limited to drug treatment; however, it is usually long-term, with high-cost and limited effectiveness (5). Vascular surgery or interventional therapy are ideal for non-extensive vascular lesions but unable to treat diffused vascular stenosis in lower extremity diabetic complications (6). Exercise can improve 
metabolism and ameliorate vascular lesions (7). However, the ability to exercise is impaired in most patients with DF. These limitations have prompted further studies on the mechanism of DF to aid the development of novel and effective treatments.

The dysfunction of vascular endothelial cells is the major cause of PAD, which has been documented in numerous studies in the past decades $(8,9)$. Therefore, angiogenic factors, such as VEGF, are beneficial for ulcer healing (10). VEGF is known to act directly on numerous types of cells, including skeletal muscle cells (11). The skeletal muscle is the main organ for sugar metabolism in humans, also acting as the exoskeleton environment for vascular endothelial cell growth. Based on the source of ATP production, skeletal muscle fibers are divided into two types: Glycolytic and oxidative, and both can be converted to each other. In patients with long-term hypertension and diabetes, the proportion of oxidative muscle fibers is gradually decreased, with increased proportions of glycolytic muscle fibers $(12,13)$. Moreover, the levels of sugar and energy metabolism in oxidative muscle fibers are higher compared with those in glycolytic muscle fibers $(14,15)$. These observations led to the present study which hypothesized that VEGF might play a role in the transformation of skeletal fiber types and help improve vascular ischemia in DF. Therefore, the aim of the present study was to investigate the mechanism and effects of VEGF-induced muscle fiber conversion in angiogenesis and the treatment of DF.

\section{Materials and methods}

Animals. All animal experiments were conducted following the Guide for the Care and Use of Laboratory Animals published by the NIH (eighth edition, updated 2011) and ARRIVE guidelines (16). In total, 22 male C57BL/6 mice (age, 8 weeks, weight, $23.14 \pm 0.65 \mathrm{~g}$ ) were purchased from Beijing Vital River Laboratory Animal Technology Co., Ltd. Mice were maintained at typical temperatures $\left(20-22^{\circ} \mathrm{C}\right)$ and humidity (40-60\%) in the Chinese People's Liberation Army (PLA) General Hospital experimental Animal Center under specific pathogen free conditions with a 12-h light/dark cycle and ad libitum access to food and water. Animal health and behavior were monitored every 2 or 3 days. All experiments were approved by the Ethics Committee of Chinese PLA General Hospital (approval no. 8157021269; Beijing, China).

Voluntary exercise training. In total, 12 C57BL/6 mice (age, 10 weeks at the start of the experiment) were divided into sedentary (sed, $n=3)$ and voluntary exercise groups $(n=9)$ in cages equipped with a voluntary running wheel (diameter, $11 \mathrm{~cm}$ ). The wheel was connected to a counter for recording $(17,18)$. After 0, 1, 2 and 4 weeks of exercise, three mice/time point were anesthetized with $3-4 \%$ isoflurane in air and sacrificed by cervical dislocation to obtain gastrocnemius tissue.

Cells. Mouse C2C12 myoblasts were purchased from Cyagen Biosciences, Inc. Human umbilical vein endothelial cells (HUVECs), PUMC-HUVEC-T1, were kindly provided by the Molecular Biology Laboratory of PLA General Hospital (purchased from the National Experimental Cell Resource Sharing Platform). C2C12 myoblasts and PUMC-HUVEC-T1 cells were maintained in DMEM high sugar culture medium
(Hyclone; Cytiva) supplemented with $10 \%$ fetal bovine serum (Gibco; Thermo Fisher Scientific, Inc.), $100 \mathrm{U} / \mathrm{ml}$ penicillin and $100 \mathrm{U} / \mathrm{ml}$ streptomycin (Gibco; Thermo Fisher Scientific, Inc.) at $37^{\circ} \mathrm{C}, 5 \% \mathrm{CO}_{2}$. To induce myotube formation, $\mathrm{C} 2 \mathrm{C} 12$ myoblasts with 60-80\% confluence were seeded in DMEM differentiation medium containing $2 \%$ horse serum (Cytiva), $100 \mathrm{U} / \mathrm{ml}$ penicillin and $100 \mathrm{U} / \mathrm{ml}$ streptomycin (Gibco; Thermo Fisher Scientific, Inc.) at $37^{\circ} \mathrm{C}$ for 5 days (19). The success of differentiation was validated by Giemsa staining of myotubes (cat. no. G4507; Sigma-Aldrich, Merck KGaA) and western blotting using anti-myosin heavy chain antibody (cat. no. sc-53095, 1:1,000, Santa Cruz Biotechnology).

For Giemsa staining, cells were fixed in $100 \%$ methanol at room temperature (RT) for $10 \mathrm{~min}$. After air dry, Giemsa stain was added and stained for $30 \mathrm{~min}$ at RT. After rinsing with deionized water, cells were examined at x20 magnification under a light microscope (DP73; Olympus Corporation).

Recombinant proteins and antibodies. Recombinant murine VEGF (rmVEGF) was purchased from PeproTech, Inc. The anti-cytochrome c oxidase (COX) IV (cat. no.ab16056, 1:2,000), anti-peroxisome proliferator-activated receptor $\gamma$ coactivator 1- $\alpha$ (PGC-1 $\alpha$; cat. no. ab54481, 1:1,000), anti-glucose transporter member (GLUT) 4 (cat. no. ab654, 1:1,000) antibodies were purchased from Abcam. The anti-PI3K (cat. no. 4292, 1:1,000), phosphorylated (p)-PI3K antibody (Tyr458/Tyr199; cat. no. 4228; 1:1,000), AMPK $\alpha$ antibody (cat. no. 2532; 1:1,000), p-AMPK $\alpha$ antibody (Thr172; cat. no. 2535; 1:500), Akt antibody (cat. no. 4685S; 1:250), p-Akt antibody (Ser473) (cat. no. 4060S; 1:250) antibodies were purchased from Cell Signaling Technology, Inc. The anti- $\beta$-actin (cat. no. 854-s, 1:2,000) was purchased from HuaBio.

Immunofluorescence on frozen sections. The center part of gastrocnemius muscle from mice trained with voluntary exercise was obtained and immediately immersed in liquid nitrogen $\left(-196^{\circ} \mathrm{C}\right)$. Tissues were embedded in optimal cutting temperature compound (cat. no. 4583; Sakura Finetek USA, Inc.) and cut into 6- $\mu$ m-thick sections. Sections were then fixed in $4 \%$ polyformaldehyde solution at RT for $10 \mathrm{~min}$, permeabilized in $0.3 \%$ Triton $\mathrm{X}$ solution, blocked with goat serum (cat. no. ZLI-9022; ZSGB-Bio; OriGene Technologies, Inc.) at RT for $30 \mathrm{~min}$, and stained with anti-CD31 (1:50, cat. no. MCA2388, Bio-Rad Laboratories) and myosin heavy chain IIa (MHCIIa) antibodies (1:200, cat. no. sc-53095, Santa Cruz Biotechnology) at $4^{\circ} \mathrm{C}$ overnight followed by incubation with FITC- (cat. no. ZF-0315, 1:300; ZSGB-Bio; OriGene Technologies, Inc.) or Alexa Fluor 594- (cat. no. ZF-0513, 1:300, ZSGB-Bio; OriGene Technologies, Inc.) conjugated secondary antibodies at RT for $30 \mathrm{~min}$. The images were captured at $\mathrm{x} 40$ magnification using a confocal microscope (TCS SP8; Leica Microsystems GmbH). The fluorescence intensity was quantified using ImageJ (version $1.52 \mathrm{a}$; National Institutes of Health) (20).

ELISA. Gastrocnemius muscle samples from mice trained with voluntary exercise were cut into small pieces $(\sim 5-\mathrm{mm})$, and quickly immersed in liquid nitrogen $\left(-196^{\circ} \mathrm{C}\right)$. Tissues were then homogenized and centrifuged at $8,000 \mathrm{x}$ g for $15 \mathrm{~min}$ at $4^{\circ} \mathrm{C}$. The supernatant was used to assay the concentration 
of VEGF (cat. no. EK0541; Boster Biological Technology) and enzyme activity of citric acid synthase (cat. no. MAK057; Sigma-Aldrich, Merck KGaA) according to manufacturer's protocols.

Lower limb ischemia model in diabetic mice and adenovirus transduction. A total of 108 -week-old male C57BL/6 mice were fed with high-fat diet (Research Diets, Inc.) for 6 weeks and then injected with $100 \mathrm{mg} / \mathrm{kg}$ streptozocin (STZ, Sigma-Aldrich; Merck KGaA) on day 0. Diabetic mice were screened for random blood glucose levels and confirmed by two consecutive tests of tail vein blood glucose of $>11 \mathrm{mmol} / 1$ on days 2 and 7 after STZ injection. On day 8 , diabetic mice were intraperitoneally injected with pentobarbital (50 mg/kg, Sigma-Aldrich; Merck KGaA) and then received surgery to ligate the femoral artery on the left lower limb, using the right lower limb as the control (skin not cut open) (21). On day 9, laser Doppler imaging apparatus (PeriCam PSI System; PIMSoft version 1.5.4.8078; Perimed, $\mathrm{AB}$ ) was used to detect the blood flow perfusion in lower limbs to ensure the ischemia was successful in seven mice (monitoring distance, $15 \mathrm{~cm}$; area height, $4.5 \mathrm{~cm}$; width, $5.0 \mathrm{~cm}$; area, $110 \mathrm{~cm}^{2}$; modeling failed in three mice, which were sacrificed immediately) (22). Adenovirus (Ad)-VEGF-green fluorescent protein (GFP) and Ad-GFP were produced by Hanbio Biotechnology Co., Ltd. based on the sequence of VEGF transcript (pAdEasy-EF1-MCS-3flag-CMV-EGFP; accession no. of VEGF, NM_001025366.2; $1 \times 10^{10} \mathrm{pfu} / \mathrm{ml}$ each). On day 10 , a total of $200 \mu \mathrm{l}$ Ad-VEGF-GFP or Ad-GFP was injected at three sites of the left gastrocnemius of ischemic diabetic mice (three mice/group, one mouse was sacrificed). A pilot experiment showed that ischemia could be released 2 weeks after surgery. Therefore, the blood flow perfusion in those mice was examined by laser Doppler imaging at 1, 3, 7 and 14 days after adenovirus transduction. The speed of blood flow under the skin was indicated as perfusion unit in different colors: Red indicated the most rapid blood flow, dark blue indicated the slowest blood flow, and yellow indicated moderate speed of blood flow $(21,22)$. To eliminate the influence of environmental factors and individual variations, the ratio of blood flow in the ischemic limb and control limb in each mouse was used to analyze the data. On day 14 , all mice were anesthetized by $3-4 \%$ isoflurane in air and sacrificed by cervical dislocation. The transfection efficiency of Ad particles was evaluated at $\mathrm{x} 40$ magnification under a fluorescence microscope by observing GFP expression in the frozen slices of skeletal muscle tissue (23).

Semi-quantitative and reverse transcription-quantitative PCR (RT-qPCR). Total RNA was extracted using TRIzol ${ }^{\circledR}$ (cat. no. 15596026, Thermo Fisher Scientific, Inc.). In total, $1 \mu \mathrm{g}$ RNA was mixed with $1 \mu \mathrm{l}$ Oligo dT Primer $(50 \mu \mathrm{M})$, $1 \mu \mathrm{ldNTP}$ Mixture (10 $\mathrm{mM}$ each) and RNase-free $\mathrm{dH}_{2} \mathrm{O}$ (fill up to $10 \mu \mathrm{l}$ volume) and incubated for $5 \mathrm{~min}$ at $65^{\circ} \mathrm{C}$, before cooling immediately on ice. This $10 \mu \mathrm{l}$ mixture was added with $4 \mu 15 \mathrm{X}$ PrimeScript ${ }^{\mathrm{TM}}$ Buffer, $0.5 \mu 1$ RNase Inhibitor (40 U/ $\mu \mathrm{l}), 1 \mu \mathrm{l}$ PrimeScript ${ }^{\mathrm{TM}}$ RTase $(200 \mathrm{U} / \mu \mathrm{l})$ and RNase Free $\mathrm{dH}_{2} \mathrm{O}$ (fill up to $20 \mu \mathrm{l}$ ) and incubated at $42^{\circ} \mathrm{C}$ for $1 \mathrm{~h}$. Inactivation of reverse transcription was performed by incubating at $95^{\circ} \mathrm{C}$ for $5 \mathrm{~min}$ and then cooled on ice
(PrimeScript ${ }^{\mathrm{TM}}$ 1st strand cDNA Synthesis Kit; Takara Biotechnology Co., Ltd.).

The expression of VEGFR1 and VEGFR2 in C2C12 myotubes was evaluated by semi-quantitative PCR. The PCR mix contained $25 \mu 12 \mathrm{X}$ Power Taq PCR MasterMix (BioTeke Corporation), $1 \mu \mathrm{l}$ cDNA, $1 \mu \mathrm{l}$ forward primer (10 $\mu \mathrm{M}), 1 \mu \mathrm{l}$ reverse primer $(10 \mu \mathrm{M})$ and $22 \mu \mathrm{l}$ nuclease-free $\mathrm{H}_{2} \mathrm{O}$. PCR reaction was performed using the following thermocycling conditions: $95^{\circ} \mathrm{C}$ for $120 \mathrm{sec}$, followed by 35 cycles of $95^{\circ} \mathrm{C}$ for $30 \mathrm{sec}, 60^{\circ} \mathrm{C}$ for $30 \mathrm{sec}$ and $72^{\circ} \mathrm{C}$ for $30 \mathrm{sec}, 72^{\circ} \mathrm{C}$ for $2 \mathrm{~min}$. The following primers were used: Mouse VEGFR1 (forward, 5'-AAAGCGCAGCCTACCTCACC-3' and reverse, 5'-AGGAGCCAAAAGAGGGTCGC-3'), mouse VEGFR2 (forward, 5'-GGTGCCTTCGGCCAAGTGAT-3' and reverse, 5'-CGATGCTCGCTGTGTGTTGC-3') and mouse $\beta$-actin (forward, 5'-CCCAGCACAATGAAGATCAAGATCAT-3' and reverse, 5'-ATCTGCTGGAAGGTGGACAGCGA-3'). Subsequently, $1 \%$ agarose gel with ethidium bromide was used for electrophoresis.

After the formation of myotubes in $\mathrm{C} 2 \mathrm{C} 12$ cells, $5,10,20 \mathrm{ng} / \mathrm{ml} \mathrm{rmVEGF}$ was added into cells incubated at $37^{\circ} \mathrm{C}$ for various durations $(6,12$ and $24 \mathrm{~h})$. Control cells were treated with $20 \mathrm{ng} / \mathrm{ml}$ BSA. qPCR was performed with TB Green Premix Ex Taq (Tli RNaseH Plus; Takara Biotechnology Co., Ltd.) using the following thermocycling conditions: $95^{\circ} \mathrm{C}$ for $30 \mathrm{sec}, 40$ cycles of $95^{\circ} \mathrm{C}$ for $5 \mathrm{sec}$ and $60^{\circ} \mathrm{C}$ for $20 \mathrm{sec}$. The gene expression levels were quantified as a fold change against GAPDH using the $2^{-\Delta \Delta \mathrm{Cq}}$ method (24). The following primers were used: mouse MHCIIa (forward, 5'-CGCAGAATCGCAAGTCAATA-3' and reverse, 5'-ATA TCTTCTGCCCTGCACCA-3'), mouse GAPDH (forward, 5'-CGTGTTCCTACCCCCAATGT-3' and reverse, 5'-TGT CATCATACTTGGCAGGTTTCT-3').

HUVEC migration assay. A total of $200 \mu 1$ HUVECs ( $2 \times 10^{5}$ cells $/ \mathrm{ml}$ in the aforementioned DMEM) were seeded into the upper Transwell chambers in triplicate (24-well plate with $8.0-\mu \mathrm{m}$ pore insert, cat. no. 3422, Corning, Inc.). The lower chamber was added $800 \mu$ l DMEM differentiation medium containing either $3 \times 10^{5}$ cells $/ \mathrm{ml}$ untreated $\mathrm{C} 2 \mathrm{C} 12$ myotubes, or $3 \times 10^{5}$ cells/ml VEGF-treated $\mathrm{C} 2 \mathrm{C} 12$ myotubes (20 ng/ml rmVEGF-treated for $12 \mathrm{~h}$ at $37^{\circ} \mathrm{C}$, but no VEGF in Transwell afterwards), or $20 \mathrm{ng} / \mathrm{ml} \mathrm{rmVEGF}$ for $24 \mathrm{~h}$ at $37^{\circ} \mathrm{C}$. The cells in the lower chamber were fixed with $100 \%$ methanol at RT for $20 \mathrm{~min}$ and stained with $0.1 \%$ crystal violet solution at room temperature for $20 \mathrm{~min}$ (Beijing Solarbio Science \& Technology Co., Ltd.) (25). A total of eight fields of view in each chamber were captured at x100 magnification using a confocal microscope (TCS SP8; Leica Microsystems GmbH).

Tubule formation of HUVECs. A total of $800 \mu 1$ HUVECs $\left(2 \times 10^{5}\right.$ cells $/ \mathrm{ml}$ in the aforementioned DMEM) were seeded into the lower Transwell chamber in triplicate (24-well plate with $8.0-\mu \mathrm{m}$ pore insert; cat. no. 3422; Corning, Inc.). The upper chamber was added $200 \mu 1$ DMEM differentiation medium containing either $3 \times 10^{5}$ cells $/ \mathrm{ml}$ untreated $\mathrm{C} 2 \mathrm{C} 12$ myotubes, or $3 \times 10^{5}$ cells $/ \mathrm{ml}$ VEGF-treated C2C12 myotubes $(20 \mathrm{ng} / \mathrm{ml}$ rmVEGF-treated for $12 \mathrm{~h}$ at $37^{\circ} \mathrm{C}$, but no VEGF in Transwell afterwards), or $20 \mathrm{ng} / \mathrm{ml} \mathrm{rmVEGF}$. After $24 \mathrm{~h}$ culture at $37^{\circ} \mathrm{C}$, nine fields of view in each chamber were captured at $\mathrm{x} 100$ 
magnification under an inverted phase contrast light microscope (TH4-200; Olympus Corporation). HUVEC tube length was analyzed using ImageJ software (version 1.52a) (26).

Glucose uptake assay. In total, $2 \times 10^{5}$ cells $/ \mathrm{ml} \mathrm{C} 2 \mathrm{C} 12$ cells were induced to differentiate into myotubes in a six-well plate in DMEM differentiation medium and then starved in serum-free DMEM for $6 \mathrm{~h}$ at $37^{\circ} \mathrm{C}$. Cells were then treated with either $20 \mathrm{ng} / \mathrm{ml} \mathrm{BSA}$ (control), or $100 \mathrm{nmol} / \mathrm{l}$ insulin (Sigma-Aldrich; Merck KGaA) or $20 \mathrm{ng} / \mathrm{ml} \mathrm{rmVEGF}$ at $37^{\circ} \mathrm{C}$ for $12 \mathrm{~h}$. The level of glucose in the supernatant was assayed according to manufacturer's instructions (cat. no. 09000240660; Shanghai Mingdian Biotechnology Co., Ltd.).

Statistical analysis. Statistical analyses were performed with GraphPad Prism software (version 8.3.0; GraphPad Software, Inc.). Data are presented as the mean \pm standard deviation and were analyzed with unpaired Student's t-test (two-tailed) or one-way analysis of variance followed by Tukey's post hoc test. $\mathrm{P}<0.05$ was considered to indicate a statistically significant difference.

\section{Results}

Voluntary exercise induces VEGF expression and skeletal fiber type switch. Mouse housing cages were first set up equipped with a voluntary running wheel (Fig. 1A). After 1, 2 and 4 weeks of exercise, mouse gastrocnemius muscle tissues were collected to investigate whether there were any changes in the muscle fiber types in those mice. Immunofluorescence staining found that the frequency of oxidized muscle fibers (red, MHCIIa-positive) was significantly increased after 1-week (46.050 \pm 0.919 vs. $36.400 \pm 0.990$; $\mathrm{P}<0.05)$, 2-week $(50.600 \pm 2.970$ vs. $36.400 \pm 0.990 ; \mathrm{P}<0.01)$, 4 -week $(60.050 \pm 1.626$ vs. $36.400 \pm 0.990 ; \mathrm{P}<0.001)$ exercise compared with that in sedentary mice (Fig. 1B). Significantly increased oxidized muscle fibers were also observed between 2- and 4 -week exercise $(50.600 \pm 2.970$ vs. $60.050 \pm 1.626$; $\mathrm{P}<0.05$; Fig. 1B). The present study proceeded to measure VEGF levels in gastrocnemius muscle by ELISA. It was found that VEGF expression in skeletal muscle samples was significantly increased compared with the sed group even after 1 week of exercise $(205.962 \pm 9.712$ vs. $449.164 \pm 15.280 \mathrm{pg} / \mathrm{ml}$; $\mathrm{P}<0.0001)$ and further increased with longer exercise duration $(556.818 \pm 22.659$ and $549.366 \pm 14.410 \mathrm{pg} / \mathrm{ml}$ after 2 or 4 weeks of exercise, respectively; both $\mathrm{P}<0.0001$ vs. sed group; Fig. 1C). Moreover, the enzyme activity of citric acid synthase in skeletal muscles was also enhanced compared with that in the sed group after 1 week of exercise $(0.029 \pm 0.002$ vs . $0.023 \pm 0.002 \mathrm{pg} / \mathrm{ml} ; \mathrm{P}<0.05)$ and further increased after 2 week $(0.036 \pm 0.001$ vs. $0.023 \pm 0.002 \mathrm{pg} / \mathrm{ml} ; \mathrm{P}<0.0001)$ and 4 week of exercise $(0.034 \pm 0.001$ vs. $0.023 \pm 0.002 \mathrm{pg} / \mathrm{ml} ; \mathrm{P}<0.001)$. The enhanced citric acid synthase activity was also observed between 1 and 2 weeks exercise $(0.029 \pm 0.002$ vs. $0.036 \pm 0.001$; $\mathrm{P}<0.01$; Fig. 1D). These data suggested that skeletal fiber type switch might be involved in VEGF-induced angiogenesis.

VEGF alone is sufficient to induce skeletal fiber type switch. The aforementioned results indicated that voluntary exercise induced VEGF expression and fiber type switch in the skeletal muscle. Subsequent experiments aimed to confirm whether VEGF or other factors were responsible for the skeletal fiber type switch. C57BL/6 mice were fed with high fat diet and then treated with $100 \mathrm{mg} / \mathrm{kg} \mathrm{STZ}$ to induce diabetes. Femoral artery ligation surgery in the left lower limb was performed in diabetic mice (Fig. S1). Ad-GFP or Ad-VEGF-GFP particles were injected into the gastrocnemius muscle. VEGF overexpression was examined by GFP expression and further confirmed using ELISA $(180.339 \pm 15.000$ vs. $653.373 \pm 55.348 \mathrm{pg} / \mathrm{ml} ; \mathrm{P}<0.001)$ (Fig. 2A and B). At 14 days after adenovirus intramuscular injection, the content of oxidized muscle fibers (red, MHCIIa) markedly increased following VEGF overexpression (Fig. 2C). Similarly, the activity of citric acid synthase in skeletal muscle was also significantly enhanced $(0.018 \pm 0.002$ vs. $0.030 \pm 0.003 \mu \mathrm{mol} / \mathrm{min} / \mathrm{ml} ; \mathrm{P}<0.01$; Fig. 2D). Of note, blood perfusion in the ischemic limb was significantly improved in the Ad-VEGF-GFP group compared with that in the Ad-GFP mice at days 3, 7 and 14 (all $\mathrm{P}<0.05$ ), suggesting that VEGF alone was sufficient to induce muscle fiber type switch and improved ischemia in a diabetic murine model of hind limb ischemia (Fig. 3A and B).

VEGF-induced oxidized muscle fibers promote the migration and tubule formation of HUVECs. The present study has showed that VEGF improved blood perfusion and induced muscle fiber type switch. Subsequently, whether the changes of muscle fiber types could influence angiogenesis was assessed using $\mathrm{C} 2 \mathrm{C} 12$ myoblasts and HUVECs. C2C12 myoblasts were cultured and differentiated into myotubes, which was validated by the changes in morphology, which changed from round shape to elongated tubule shape (Fig. S2A-D) and the expression of MHC (Fig. S2E). The expression of VEGFR1 in C2C12 myotubes was confirmed by semi-quantitative PCR (Fig. S3A). Different concentrations $(5,10$ and $20 \mathrm{ng} / \mathrm{ml})$ of the recombinant murine VEGF proteins (rmVEGF) were added into $\mathrm{C} 2 \mathrm{C} 12$ myotubes for various durations to screen for the optimal treatment protocol. RT-qPCR showed treatment of $20 \mathrm{ng} / \mathrm{ml}$ VEGF for $12 \mathrm{~h}$ had the greatest effect on MHCIIa expression (Fig. S3B), which was used in subsequent experiments. The expression of oxidized muscle fibers (MHCIIa, red) in $\mathrm{C} 2 \mathrm{C} 12$ myotubes also increased after treating with $20 \mathrm{ng} / \mathrm{ml}$ VEGF for $12 \mathrm{~h}$, but not with $20 \mathrm{ng} / \mathrm{ml} \mathrm{BSA} \mathrm{(Fig.} \mathrm{S3C).}$

HUVECs were cultured alone, with $\mathrm{C} 2 \mathrm{C} 12$ myotubes, VEGF (positive control) or VEGF-treated $\mathrm{C} 2 \mathrm{C} 12$ myotubes in Transwell chambers. The migrated HUVECs were then quantified and normalized (HUVECs, 100 $\pm 20.84 \%$; HUVECs + C2C12, 103.1 \pm 7.07\%; HUVECs + rmVEGF, 373.5 $\pm 9.184 \%$; HUVECs + rmVEGF-treated C2C12, 262.2 $\pm 12.37 \%$ ). Treatment of VEGF significantly promoted HUVEC migration $(\mathrm{P}<0.0001$, HUVECs + rmVEGF vs. HUVECs or HUVECs + C2C12; Fig. 4A-E). Co-culturing of VEGF-treated $\mathrm{C} 2 \mathrm{C} 12$ myotubes also significantly enhanced HUVEC migration $(\mathrm{P}<0.0001$; HUVECs + rmVEGF-treated $\mathrm{C} 2 \mathrm{C} 12$ vs. HUVECs or HUVECs + C2C12; Fig. 4A-E).

Similarly, the tubule formation of HUVEVs were quantified and normalized (HUVECs, $100 \pm 16.67 \%$; HUVECs $+\mathrm{C} 2 \mathrm{C} 12,122.2 \pm 20.97 \%$; HUVECs + rmVEGF, $844.4 \pm 91.41 \%$;

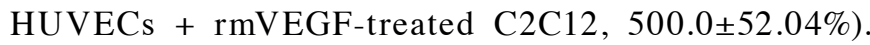


A
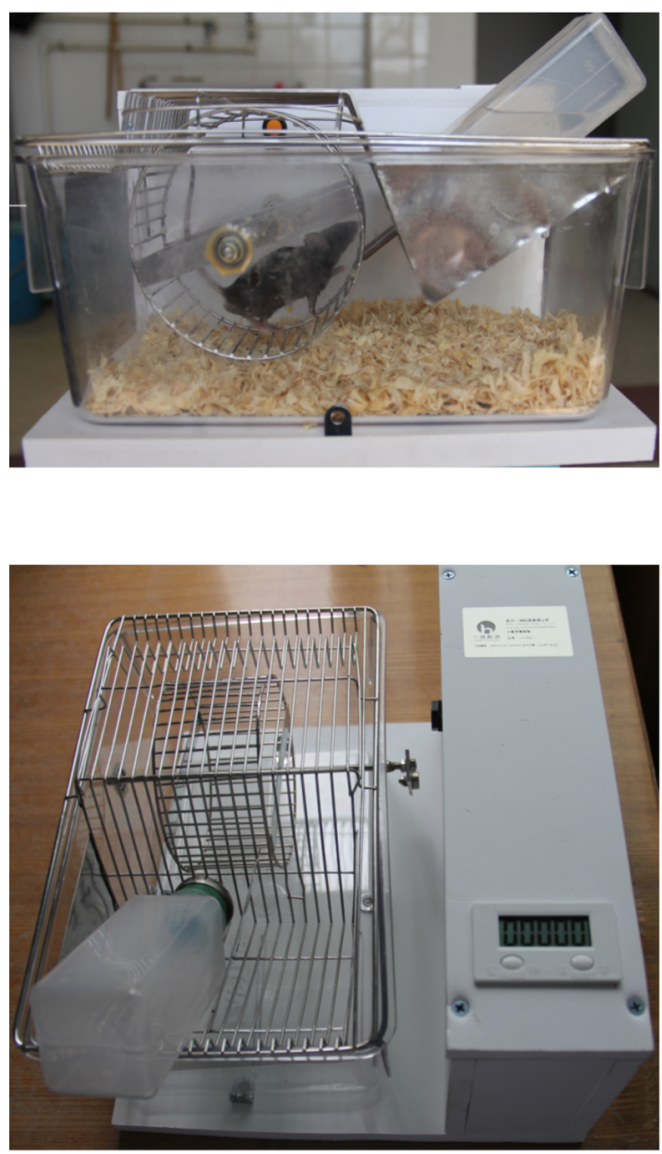

C

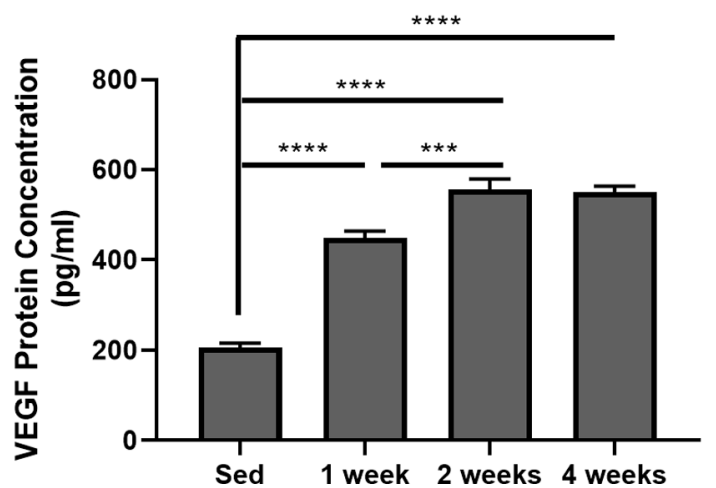

B
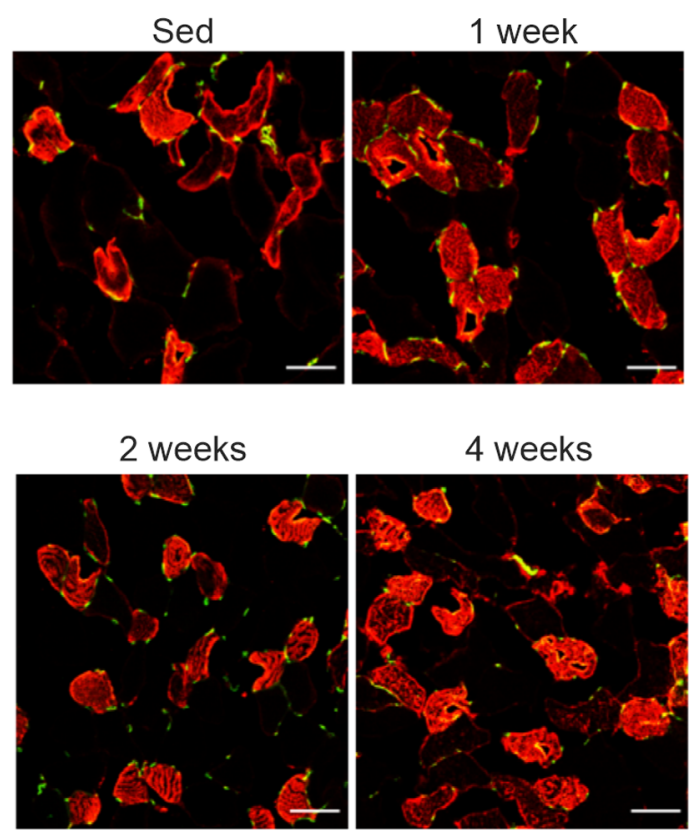

$* * *$

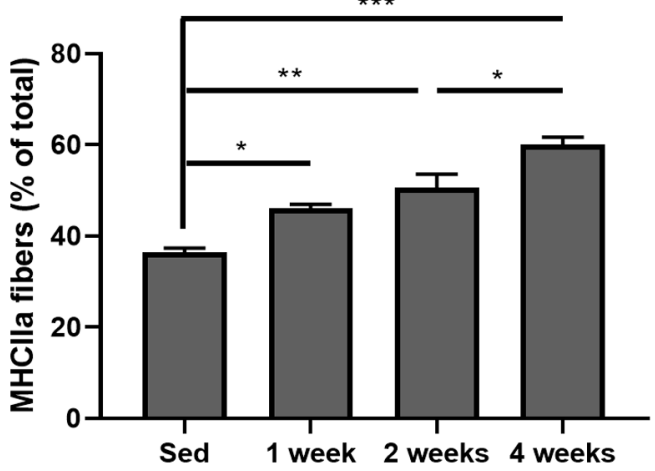

D

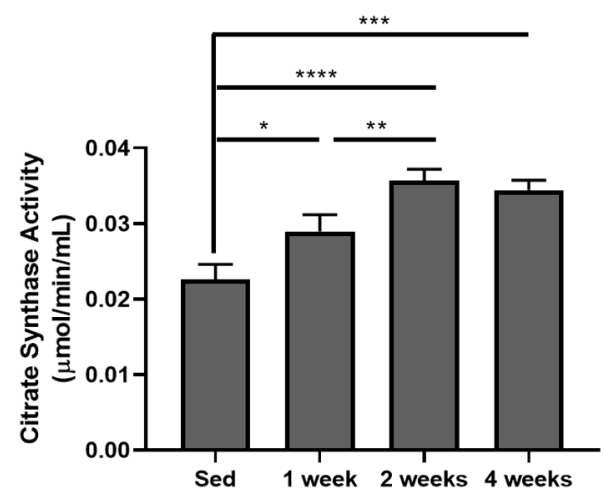

Figure 1. Voluntary running induces skeletal muscle fiber switch and VEGF expression. (A) Voluntary running model setup. (B) Skeletal muscle adaptation in mice after long-term voluntary running. Immunofluorescence staining of endothelial cells (CD31, green) and MHCIIa fibers (red) in the skeletal muscle samples of sedentary mice and mice after 1,2 and 4 weeks of training. The frequency of MHCIIa fibers at different training durations was analyzed. Scale bars, $100 \mu \mathrm{m}$. (C) VEGF concentration in gastrocnemius samples. (D) Citrate synthase activity in gastrocnemius samples at the indicated time points. Data are presented as the mean \pm standard deviation and are representative of two independent experiments. $\mathrm{n}=3$ mice/group in each independent experiment. ${ }^{*} \mathrm{P}<0.05$, ${ }^{* * *} \mathrm{P}<0.01,{ }^{* * * *} \mathrm{P}<0.001$ and ${ }^{* * * * *} \mathrm{P}<0.0001$. Sed, sedentary; VEGF, vascular endothelial growth factor; MHC, myosin heavy chain.

Both VEGF treatment $(\mathrm{P}<0.0001$, HUVECs + rmVEGF vs. HUVECs or HUVECs $+\mathrm{C} 2 \mathrm{C} 12)$ and co-culture with VEGF-treated $\mathrm{C} 2 \mathrm{C} 12$ myotubes $(\mathrm{P}<0.0001$ for HUVECs + rmVEGF-treated C2C12 vs. HUVECs or HUVECs + C2C12 group) significantly enhanced HUVEC tubule formation (Fig. 4F-J).
Glucose consumption and PI3K/Akt/AMPK signaling pathways are involved in the VEGF-induced oxidization of C2C12 myotubes. The molecular mechanism underlying VEGF-induced oxidization of $\mathrm{C} 2 \mathrm{C} 12$ myotubes was subsequently investigated. Since skeletal muscle is one of the most important organs involved in glucose consumption, it was first 
A

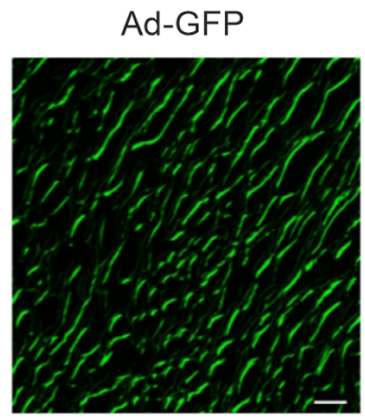

C Ad-GFP

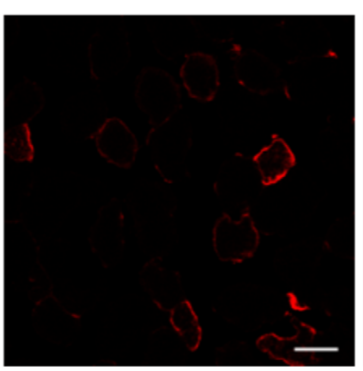

Ad-VEGF-GFP

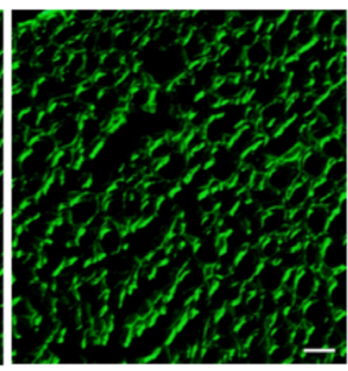

Ad-VEGF-GFP

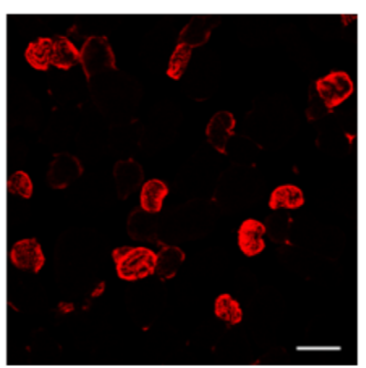

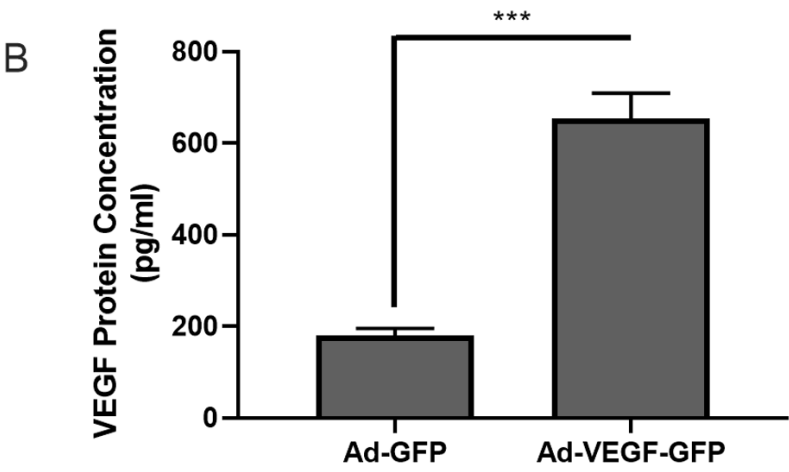

D

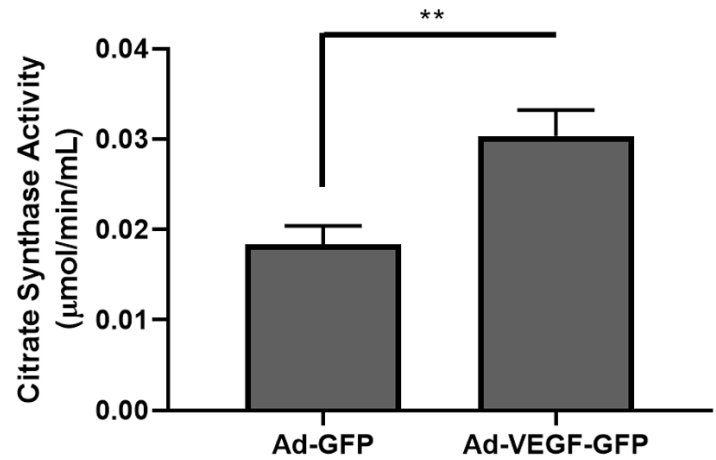

Figure 2. VEGF overexpression in gastrocnemius induces muscle fiber type switch in ischemic mice. (A) GFP marker levels 14 days after Ad-VEGF-GFP and Ad-GFP injection in skeletal muscle tissues were assessed by fluorescence microscopy. Scale bar $=200 \mu \mathrm{m}$. (B) VEGF levels at 14 days as determined using ELISA. (C) Immunofluorescence staining of MHCIIa fibers (red) of ischemic gastrocnemius following treatment with Ad-VEGF-GFP or Ad-GFP. Scale Bars, $100 \mu \mathrm{m}$. (D) Citrate synthase activity in gastrocnemius. Data are presented as the mean \pm standard deviation and are representative of 2 independent experiments. $\mathrm{n}=3$ mice/group in each independent experiment. ${ }^{* *} \mathrm{P}<0.01$ and ${ }^{* * *} \mathrm{P}<0.001$. GFP, green fluorescent protein; Ad, adenovirus; VEGF, vascular endothelial growth factor.

A

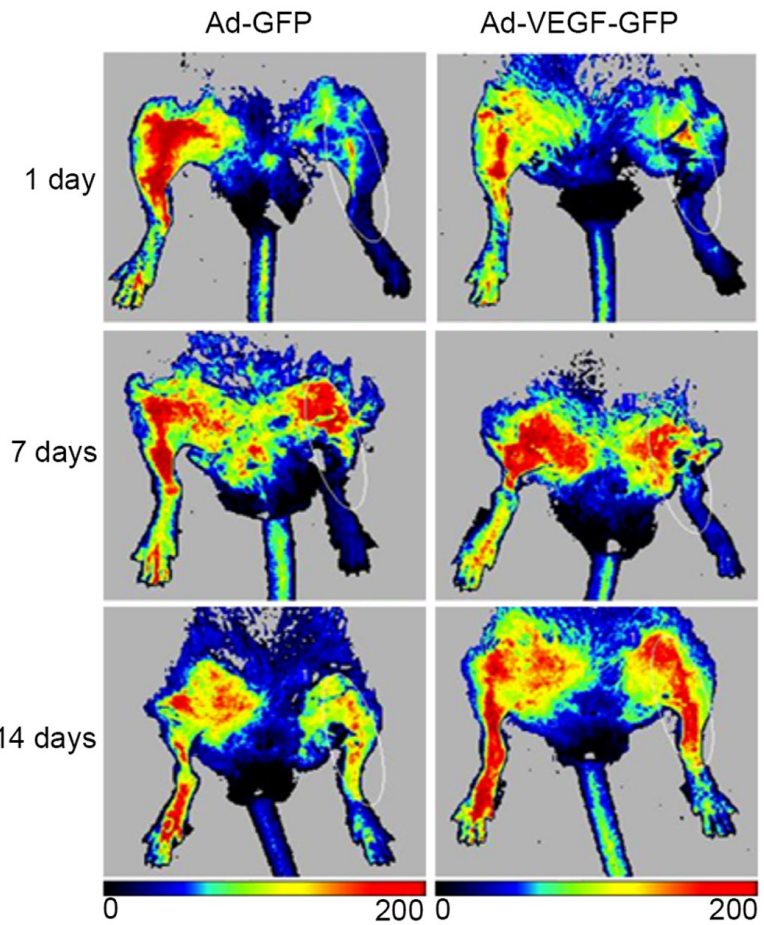

B

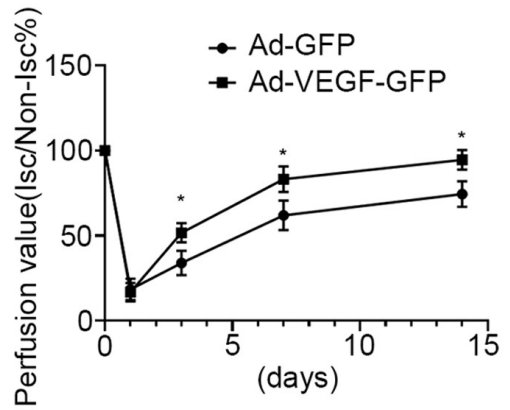

Figure 3. VEGF overexpression in gastrocnemius improves blood perfusion in ischemic limbs. (A) Laser Doppler monitoring of blood flow at the indicated time points after injecting Ad-GFP alone or Ad-VEGF-GFP. The color scale of all images was analyzed by setting the lowest perfusion value to 0 and the highest perfusion value to 200. (B) Blood flow imaging data were calculated by normalizing the ischemic limb data to the non-ischemic limb values. Data are presented as the mean \pm standard deviation and are representative of two independent experiments. $\mathrm{n}=3$ mice/group in each independent experiment. ${ }^{*} \mathrm{P}<0.05$ vs. Ad-GFP. GFP, green fluorescent protein; Ad, adenovirus; Isc, ischemic; VEGF, vascular endothelial growth factor. 


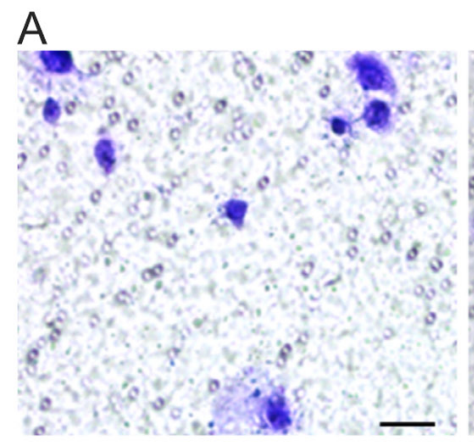

C

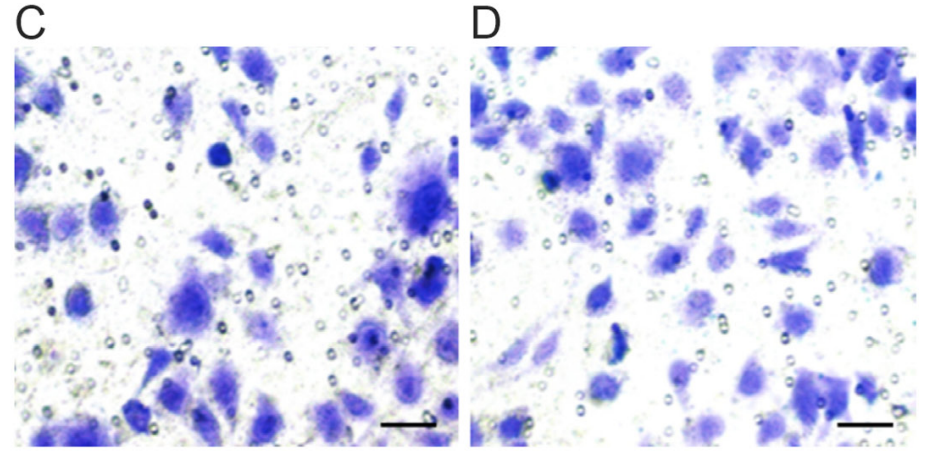

F

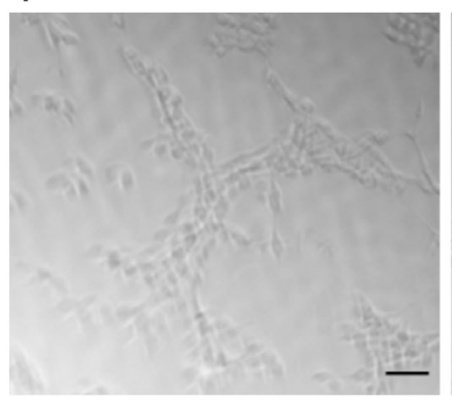

H

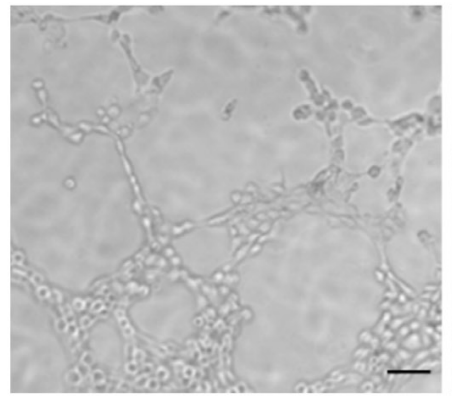

B

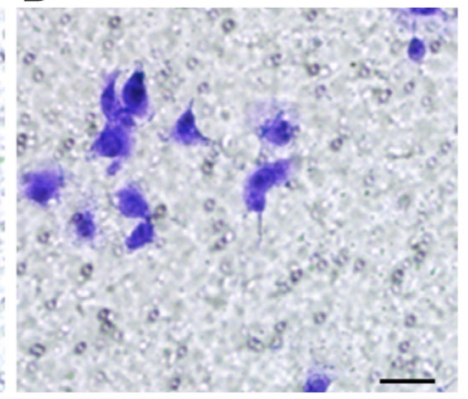

\section{D}

G

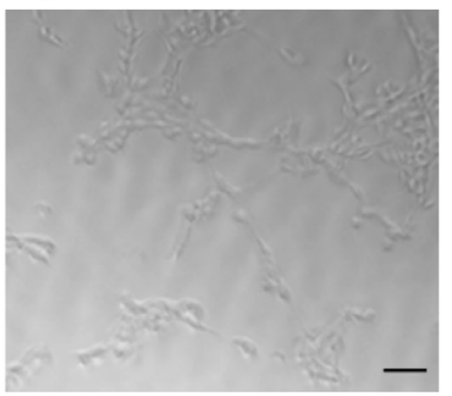

I

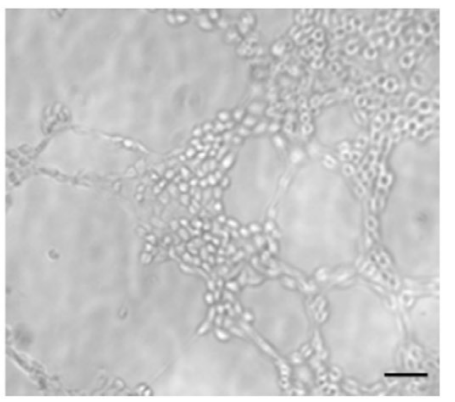

E

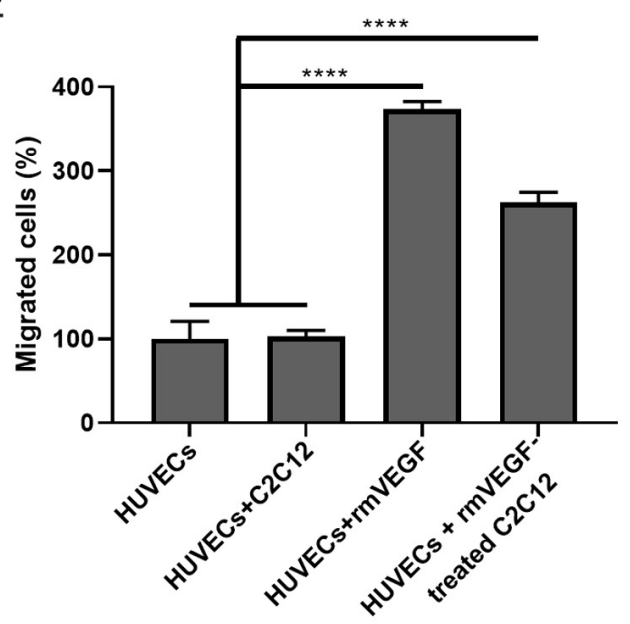

J

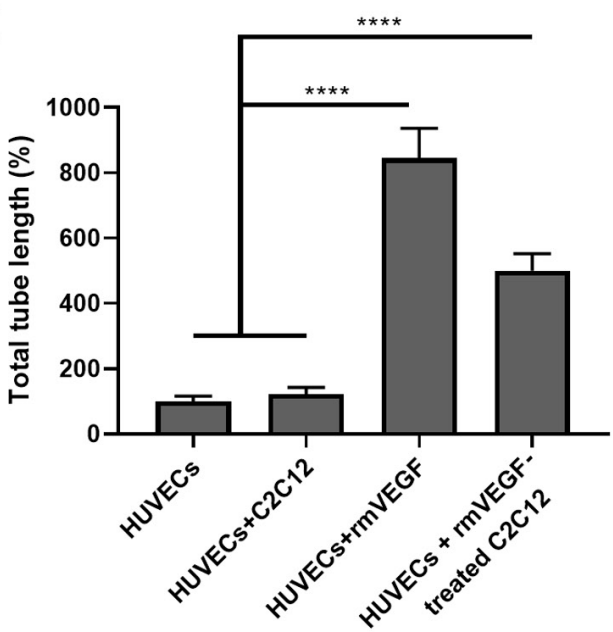

Figure 4. rmVEGF-treated oxidative fibers enhance the migration and tubule formation of HUVECs after a 24-h culture in Transwell chambers. Crystal violet staining of migrated HUVECs. (A) HUVECs alone. (B) HUVECs with C2C12 myotubes. (C) rmVEGF-treated HUVECs. (D) HUVECs with rmVEGF-treated $\mathrm{C} 2 \mathrm{C} 12$ cells. Scale bars, $50 \mu \mathrm{m}$. (E) The number of migrated cells in each condition was normalized to the HUVECs group and analyzed. An inverted microscope was used to assess the tubule formation of HUVECs. (F) HUVECs alone. (G) HUVECs with C2C12 myotubes. (H) rmVEGF-treated HUVECs. (I) HUVECs with rmVEGF-treated C2C12 cells. Scale bars, $50 \mu \mathrm{m}$. (J) The length of the formed tubes in each condition was normalized to the HUVECs group and analyzed. Data are presented as the mean \pm standard deviation and are combined from three independent experiments. ${ }^{* * * *} \mathrm{P}<0.0001$. HUVEC, human umbilical vein endothelial cells; rmVEGF, recombinant murine VEGF.

evaluated whether VEGF treatment altered glucose consumption in $\mathrm{C} 2 \mathrm{C} 12$ tubule. Compared with the control group (BSA treated), glucose consumption in the VEGF group was significantly increased $(0.829 \pm 0.150$ vs. $2.126 \pm 0.220 \mathrm{mmol} / \mathrm{l}$; $\mathrm{P}<0.001$; Fig. 5A), which was significantly lower compared with the positive control insulin group $(2.918 \pm 0.182 \mathrm{mmol} / \mathrm{l})$.
The expression of molecules involved in glucose consumption, including PGC-1 $\alpha$, GLUT4 and COX IV, was markedly increased following VEGF treatment (Fig. 5B). Furthermore, several pathways, including PI3K, Akt and AMPK signaling, were activated in VEGF-treated cells, but not in BSA-treated cells (Fig. 5C). 
A

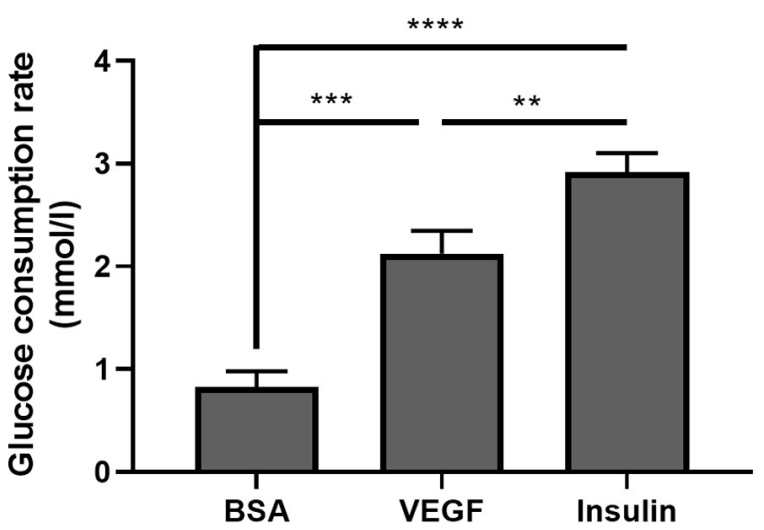

C

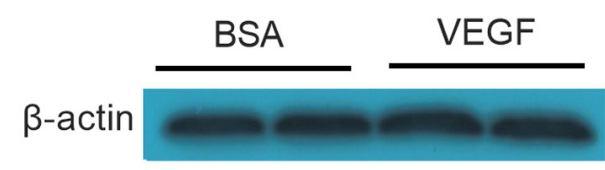

$\mathrm{PI} 3 \mathrm{~K}$

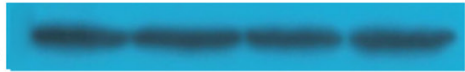

$\mathrm{p}-\mathrm{PI3K}=-\ldots$

Akt

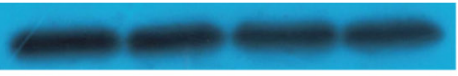

p-Akt

AMPK

p-AMPK
B

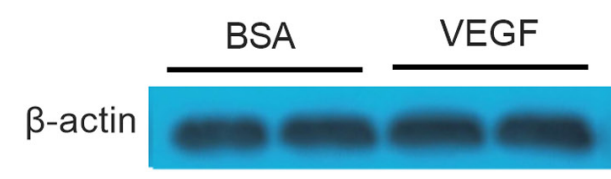

Glut4
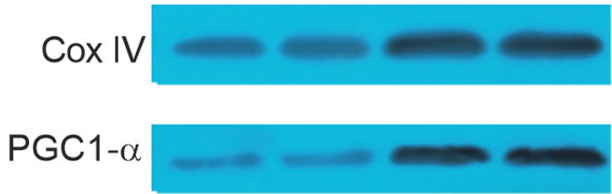

Figure 5. Molecular mechanism of the induction of oxidative muscle fibers by rmVEGF. (A) Effect of VEGF on the glucose consumption of C2C12 myotubes. (B) Representative western blots for PGC-1 $\alpha$, GLUT4 and COX IV in C2C12 myotubes. (C) Representative western blots for total and phosphorylated PI3K, Akt, and AMPK protein levels in $\mathrm{C} 2 \mathrm{C} 12$ myotubes. Data are presented as the mean \pm standard deviation and are representative of two independent experiments performed in triplicate. ${ }^{* *} \mathrm{P}<0.01,{ }^{* * * *} \mathrm{P}<0.001$ and ${ }^{* * * * *} \mathrm{P}<0.0001$. PGC- $1 \alpha$, peroxisome proliferator-activated receptor $\gamma$ coactivator- $1 \alpha$; GLUT4, anti-solute carrier family 2 facilitated glucose transporter member 4; COX IV, cytochrome c oxidase IV; rmVEGF, recombinant murine VEGF.

\section{Discussion}

The present study indicated that VEGF could induce the switch of muscle fiber types by promoting the formation of oxidative fibers in vivo and in vitro. Furthermore, the present study showed that VEGF-induced oxidization of muscle fibers improved migration and tubule formation of HUVECs. In addition, the present study provided the molecular mechanism for VEGF-induced oxidization of muscle fibers. These data may provide a novel insight into VEGF-mediated therapy in DF.

Voluntary exercise in the running wheel for 1 week was sufficient to induce the increase in the proportion of oxidative skeletal muscle fibers and the activity of citric acid synthase, which is consistent with a previous study showing that exercise could promote skeletal muscle type transformation and vascular angiogenesis (27). However, multiple myokines, including VEGF, are also influenced by exercise (28-30).
Therefore, in subsequent experiments, adenoviruses were injected into the skeletal muscle to locally upregulate VEGF expression. Ameliorated ischemia in mice with DF was observed, suggesting that VEGF in the muscle alone is sufficient to induce angiogenesis.

Skeletal muscles consist of a variety of fiber types with different functions. Based on the expression of the main myosin heavy chain subtypes, rodent fibers present with I, IIa, IId/x and IIb subtypes, while humans present with I, IIa, and IId/x subtypes (4). According to the oxidation capacity, rodent skeletal muscles are divided into oxidized fibers (I and IIa) and glycolytic fibers (IIb and IId/x). Under normal conditions, the number of oxidized and glycolytic skeletal muscle fibers is balanced but these fiber types may be readily transformed into each other in a number of settings. For example, aerobic exercise can induce the transformation of glycolytic muscle fibers into oxidized muscle fibers, characterized by a higher mitochondrial content, which 
was also observed in the present study (31-33). VEGF deficiency in mouse skeletal muscle abrogated exercise-induced angiogenesis and the increase in the proportion of oxidative fibers, indicating the importance of VEGF originating from muscles (32).

It was further determined whether the fiber type of skeletal muscle had an effect on vascular endothelial cell activity. Due to the lack of VEGF knockout mice, the present study was unable to fully analyze the mechanism of VEGF-mediated muscle fiber type switch and vascular angiogenesis in vivo. Instead, the commonly used myoblast ( $22 \mathrm{C} 12$ cells) and epithelial (PUMC-HUVEC-T1 cells) cell lines were used to investigate the role of oxidized muscle fibers on vascular angiogenesis. It was found that VEGF-oxidized C2C12 myoblasts promoted the migration and tubule formation of HUVECs, confirming the close association between oxidative muscle fibers and angiogenesis (34).

There are four muscle fiber types found in mice. Different subtypes of muscle fibers have distinct mitochondrial characteristics $(35,36)$. MHCIIa-positive oxidative fibers exhibit high mitochondrial content and fusion rates (35). PGC-1 $\alpha$ is an essential regulator in mitochondrial biogenesis (37). In addition, it was demonstrated that it plays an important role in exercise-induced adaptation of skeletal muscle $(31,38)$. Systemic or muscle-specific knockout PGC-1 $\alpha$ resulted in a decrease in the ratio of oxidized muscle fibers (39). In addition, specific expression of PGC-1 $\alpha$ in skeletal muscle induced oxidized muscle fibers (40). To the best of our knowledge, a limited number of studies have examined the effects of VEGF on PGC1- $\alpha$ and mitochondrial biogenesis. In adipose and brain tissues, treatment with VEGF increased PGC1- $\alpha$ expression and promoted mitochondrial biogenesis $(41,42)$. However, VEGF facilitated the cytoplasmic localization of PGC1- $\alpha$ in endothelial cells (43). The present study observed increased expression of PGC-1 $\alpha$ in VEGF-treated $\mathrm{C} 2 \mathrm{C} 12$ myoblasts, suggesting that the changes of skeletal muscle type mediated by VEGF were possibly mediated by PGC-1 $\alpha$. Meanwhile, an increased mitochondria content in oxidative muscle fibers was also suggested by the enhanced activity of citric acid synthase and increased COX IV expression.

Glucose is the major energy source for skeletal muscles and skeletal muscle is the organ which consumes the largest amount of glucose in the body (44). Several GLUTs are expressed in muscles to facilitate the transportation of glucose into cells (45). GLUT1 and GLUT3 are selectively expressed in fetal and regenerating fibers $(46,47)$. GLUT4 is the main glucose transporter in skeletal muscle, and highly expressed in oxidative fibers (48). It was found that oxidized muscle fibers expressed higher levels of GLUT4, indicating the increased glucose uptake capacity of skeletal muscle to improve the hyperglycemic conditions. The present study observed an elevated expression level of GLUT4 protein in C2C12 myotubes following VEGF treatment, which might facilitate the consumption of glucose and mitochondrial biogenesis.

Although the present study found that an increase of VEGF in the skeletal muscle could promote angiogenesis in vitro and alleviate lower limb ischemia in the diabetic mice, several limitations exist. First, the present study did not use a tissue-specific promoter in the adenovirus, which means that rather than myofibers, other cells could have been transfected with the VEGF gene. Although the present study performed in vitro experiments to assess the effects of VEGF-treated myofibers on angiogenesis, considering the complexity in vivo, further studies, such as utilizing adenoviruses containing a skeletal muscle specific promoter or transgenic mice with skeletal muscle-specific VEGF overexpression, are required for further clarification. Second, the present study used femoral artery ligation to induce ischemia. Although it is widely used to mimic ischemia in the lower limb of patients with DF, this acute lesion may not fully mimic the chronic ischemia in patients. Further studies are required to utilize a novel mouse model to better mimic the process of PAD in diabetic patients.

In conclusion, the present study extended prior observations of the protective effects of VEGF in DF by inducing the conversion of skeletal muscle fiber types and supported the potential therapeutic utility of VEGF in the future.

\section{Acknowledgements}

Not applicable.

\section{Funding}

This work is supported by the Shenzhen Municipal Science and Technology Innovation Committee Project (grant no. KCXFZ202002011010445, JCYJ20160422150209240), China Postdoctoral Science Foundation (grant no. 2014M562547), National Natural Science Foundation of China (grant no. 81550035) and Natural science foundation of Guangdong province (grant no. 2020A1515010085).

\section{Availability of data and materials}

The datasets used and/or analyzed in the current study are available from the corresponding author on reasonable request.

\section{Authors' contributions}

LK and XF discussed and designed the study, and critically edited the manuscript. LJ and HBW conducted the experiments and analyzed the data. PZ and HW analyzed the data and wrote the manuscript. LJ and HBW confirm the authenticity of all the raw data. All authors read and approved the final version of the manuscript.

\section{Ethics approval and consent to participate}

All experiments were approved by the Ethics Committee of Chinese PLA General Hospital (approval no. 8157021269; Beijing, China).

\section{Patient consent for publication}

Not applicable.

\section{Competing interests}

The authors declare that they have no competing interests. 


\section{References}

1. Boulton AJ, Vileikyte L, Ragnarson-Tennvall G and Apelqvist J: The global burden of diabetic foot disease. Lancet 366 : $1719-1724,2005$

2. Johannesson A, Larsson GU, Ramstrand N, Turkiewicz A, Wiréhn $\mathrm{AB}$ and Atroshi I: Incidence of lower-limb amputation in the diabetic and nondiabetic general population: A 10-year population-based cohort study of initial unilateral and contralateral amputations and reamputations. Diabetes Care 32: 275-280, 2009.

3. Prompers L, Schaper N, Apelqvist J, Edmonds M, Jude E, Mauricio D, Uccioli L, Urbancic V, Bakker K, Holstein P, et al Prediction of outcome in individuals with diabetic foot ulcers: Focus on the differences between individuals with and without peripheral arterial disease. The EURODIALE study. Diabetologia 51: 747-755, 2008.

4. Prompers L, Huijberts M, Apelqvist J, Jude E, Piaggesi A Bakker K, Edmonds M, Holstein P, Jirkovska A, Mauricio D, et al High prevalence of ischaemia, infection and serious comorbidity in patients with diabetic foot disease in Europe. Baseline results from the Eurodiale study. Diabetologia 50: 18-25, 2007.

5. American Diabetes Association: Peripheral arterial disease in people with diabetes. Diabetes Care 26: 3333-3341, 2003.

6. Guo X, Shi Y, Huang X, Ye M, Xue G and Zhang J: Features analysis of lower extremity arterial lesions in 162 diabetes patients. J Diabetes Res 2013: 781360, 2013.

7. Adams V and Linke A: Impact of exercise training on cardiovascular disease and risk. Biochim Biophys Acta Mol Basis Dis 1865: 728-734, 2019.

8. Brevetti G, Silvestro A, Schiano V and Chiariello M: Endothelial dysfunction and cardiovascular risk prediction in peripheral arterial disease: Additive value of flow-mediated dilation to ankle-brachial pressure index. Circulation 108: 2093-2098, 2003.

9. Daiber A, Steven S, Weber A, Shuvaev VV, Muzykantov VR, Laher I, Li H, Lamas S and Münzel T: Targeting vascular (endothelial) dysfunction. Br J Pharmacol 174: 1591-1619, 2017

10. Senger DR, Galli SJ, Dvorak AM, Perruzzi CA, Harvey VS and Dvorak HF: Tumor cells secrete a vascular permeability factor that promotes accumulation of ascites fluid. Science 219 : 983-985, 1983

11. Germani A, Di Carlo A, Mangoni A, Straino S, Giacinti C, Turrini P, Biglioli P and Capogrossi MC: Vascular endothelial growth factor modulates skeletal myoblast function. Am J Pathol 163: 1417-1428, 2003.

12. Yan Z, Okutsu M, Akhtar YN and Lira VA: Regulation of exercise-induced fiber type transformation, mitochondria biogenesis, and angiogenesis in skeletal muscle. J Appl Physiol (1985) 110: 264-274, 2011.

13. Oberbach A, Bossenz Y, Lehmann S, Niebauer J, Adams V, Paschke R, Schön MR, Blüher M and Punkt K: Altered fiber distribution and fiber-specific glycolytic and oxidative enzyme activity in skeletal muscle of patients with type 2 diabetes. Diabetes Care 29: 895-900, 2006.

14. Picard M, Hepple RT and Burelle Y: Mitochondrial functional specialization in glycolytic and oxidative muscle fibers: Tailoring the organelle for optimal function. Am J Physiol Cell Physiol 302: C629-C641, 2012.

15. van Weel V, Deckers MML, Grimbergen JM, van Leuven KJ, Lardenoye JH, Schlingemann RO, van Nieuw Amerongen GP, van Bockel JH, van Hinsbergh VW and Quax PH: Vascular endothelial growth factor overexpression in ischemic skeletal muscle enhances myoglobin expression in vivo. Circ Res 95: $58-66,2004$

16. McGrath JC and Lilley E: Implementing guidelines on reporting research using animals (ARRIVE etc.): New requirements for publication in BJP. Br J Pharmacol 172: 3189-3193, 2015.

17. Novak CM, Burghardt PR and Levine JA: The use of a running wheel to measure activity in rodents: Relationship to energy balance, general activity, and reward. Neurosci Biobehav Rev 36 : 1001-1014, 2012

18. Waters RE, Rotevatn S, Li P, Annex BH and Yan Z: Voluntary running induces fiber type-specific angiogenesis in mouse skeletal muscle. Am J Physiol Cell Physiol 287: C1342-C1348, 2004

19. Thinakaran G, Ojala J and Bag J: Expression of c-jun/AP-1 during myogenic differentiation in mouse $\mathrm{C} 2 \mathrm{C} 12$ myoblasts. FEBS Lett 319: 271-276, 1993.

20. Jensen EC: Quantitative analysis of histological staining and fluorescence using ImageJ. Anat Rec (Hoboken) 296: 378-381, 2013.
21. Padgett ME, McCord TJ, McClung JM and Kontos CD: methods for acute and subacute murine hindlimb Ischemia. J Vis Exp 112: 54166, 2016.

22. Tokudome T, Kishimoto I, Yamahara K, Osaki T, Minamino N, Horio T, Sawai K, Kawano Y, Miyazato M, Sata M, et al: Impaired recovery of blood flow after hind-limb ischemia in mice lacking guanylyl cyclase-A, a receptor for atrial and brain natriuretic peptides. Arterioscler Thromb Vasc Biol 29: 1516-1521, 2009.

23. Jockusch $\mathrm{H}$ and Eberhard D: Green fluorescent protein as a tracer in chimeric tissues: The power of vapor fixation. Methods Mol Biol 411: 145-154, 2007

24. Livak KJ and Schmittgen TD: Analysis of relative gene expression data using real-time quantitative PCR and the 2(-Delta Delta C(T)) method. Methods 25: 402-408, 2001.

25. Ariyanti AD, Sisjayawan J, Zhang J, Zhang JQ, Wang GX, Miyagishi M, Wu SR and Kasim V: Elevating VEGF-A and PDGF-BB secretion by salidroside enhances neoangiogenesis in diabetic hind-limb ischemia. Oncotarget 8: 97187-97205, 2017.

26. Liu N, Ding D, Hao W, Yang F, Wu X, Wang M, Xu X, Ju Z, Liu JP, Song Z, et al: hTERT promotes tumor angiogenesis by activating VEGF via interactions with the Sp1 transcription factor. Nucleic Acids Res 44: 8693-8703, 2016.

27. Delavar H, Nogueira L, Wagner PD, Hogan MC, Metzger D and Breen EC: Skeletal myofiber VEGF is essential for the exercise training response in adult mice. Am J Physiol Regul Integr Comp Physiol 306: R586-R595, 2014

28. Huh JY: The role of exercise-induced myokines in regulating metabolism. Arch Pharm Res 41: 14-29, 2018.

29. Pedersen BK and Febbraio MA: Muscles, exercise and obesity: Skeletal muscle as a secretory organ. Nat Rev Endocrinol 8: 457-465, 2012

30. Wrann CD, White JP, Salogiannnis J, Laznik-Bogoslavski D, Wu J, Ma D, Lin JD, Greenberg ME and Spiegelman BM: Exercise induces hippocampal BDNF through a PGC-1 $\alpha / F N D C 5$ pathway. Cell Metab 18: 649-659, 2013.

31. Birot OJG, Koulmann N, Peinnequin A and Bigard XA: Exercise-induced expression of vascular endothelial growth factor mRNA in rat skeletal muscle is dependent on fibre type. J Physiol 552: 213-221, 2003.

32. Cannon DT, Rodewohl L, Adams V, Breen EC and Bowen TS: Skeletal myofiber VEGF deficiency leads to mitochondrial, structural, and contractile alterations in mouse diaphragm. J Appl Physiol (1985) 127: 1360-1369, 2019.

33. Leick L, Hellsten Y, Fentz J, Lyngby SS, Wojtaszewski JF, Hidalgo $\mathrm{J}$ and Pilegaard $\mathrm{H}$ : PGC-1alpha mediates exercise-induced skeletal muscle VEGF expression in mice. Am J Physiol Endocrinol Metab 297: E92-E103, 2009.

34. Matsakas A, Yadav V, Lorca S, Evans RM and Narkar VA: Revascularization of ischemic skeletal muscle by estrogen-related receptor- $\gamma$. Circ Res 110: 1087-1096, 2012

35. Mishra P, Varuzhanyan G, Pham AH and Chan DC: Mitochondrial dynamics is a distinguishing feature of skeletal muscle fiber types and regulates organellar compartmentalization. Cell Metab 22: 1033-1044, 2015.

36. Hood DA, Memme JM, Oliveira AN and Triolo M: Maintenance of skeletal muscle mitochondria in health, exercise, and aging. Annu Rev Physiol 81: 19-41, 2019.

37. Fernandez-Marcos PJ and Auwerx J: Regulation of PGC-1 $\alpha$, a nodal regulator of mitochondrial biogenesis. Am J Clin Nutr 93 (Suppl): 884S-890S, 2011.

38. Chinsomboon J, Ruas J, Gupta RK, Thom R, Shoag J, Rowe GC, Sawada N, Raghuram S and Arany Z: The transcriptional coactivator PGC-1alpha mediates exercise-induced angiogenesis in skeletal muscle. Proc Natl Acad Sci USA 106: 21401-21406, 2009.

39. Handschin C, Chin S, Li P,Liu F, Maratos-Flier E, Lebrasseur NK, Yan Z and Spiegelman BM: Skeletal muscle fiber-type switching, exercise intolerance, and myopathy in PGC-1alpha muscle-specific knock-out animals. J Biol Chem 282: 30014-30021, 2007.

40. Lin J, Wu H, Tarr PT, Zhang CY, Wu Z, Boss O, Michael LF, Puigserver P, Isotani E, Olson EN, et al: Transcriptional co-activator PGC-1 alpha drives the formation of slow-twitch muscle fibres. Nature 418: 797-801, 2002.

41. Zhao Y, Li X, Yang L, Eckel-Mahan K, Tong Q, Gu X, Kolonin MG and Sun K: Transient overexpression of vascular endothelial growth factor a in adipose tissue promotes energy expenditure via activation of the sympathetic nervous system. Mol Cell Biol 38: e00242-18, 2018.

42. Liu X, Chu B, Jin S, Li M, Xu Y, Yang H, Feng Z, Bi J and Wang P: Vascular endothelial growth factor alleviates mitochondrial dysfunction and suppression of mitochondrial biogenesis in models of Alzheimer's disease. Int J Neurosci 131: 154-162, 2021. 
43. Wright GL, Maroulakou IG, Eldridge J, Liby TL, Sridharan V, Tsichlis PN and Muise-Helmericks RC: VEGF stimulation of mitochondrial biogenesis: Requirement of AKT3 kinase. FASEB J 22: 3264-3275, 2008.

44. Mészáros K, Lang CH, Bagby GJ and Spitzer JJ: Contribution of different organs to increased glucose consumption after endotoxin administration. J Biol Chem 262: 10965-10970, 1987.

45. Evans PL, McMillin SL, Weyrauch LA and Witczak CA: Regulation of skeletal muscle glucose transport and glucose metabolism by exercise training. Nutrients 11: 2432, 2019.

46. Gaster M, Beck-Nielsen H and Schroder H: Regenerating human muscle fibres express GLUT3 protein. Pflügers Arch 445 105-114, 2002.
47. Gaster M, Franch J, Staehr P, Beck-Nielsen H, Smith T and Schroder H: Induction of GLUT-1 protein in adult human skeletal muscle fibers. Am J Physiol Endocrinol Metab 279: E1191-E1195, 2000.

48. Goodyear LJ, Hirshman MF, Smith RJ and Horton ES: Glucose transporter number, activity, and isoform content in plasma membranes of red and white skeletal muscle. Am J Physiol Endocrinol Metab 261: E556-E561, 1991.

This work is licensed under a Creative Commons Attribution-NonCommercial-NoDerivatives 4.0 International (CC BY-NC-ND 4.0) License. 